\title{
Features of Reactive Power Compensation in Electrical Networks of Coal Open Pit Mines
}

\author{
Roman Belyaevsky \\ Department "Power supply of mining \\ and industrial enterprises" \\ T.F. Gorbachev Kuzbass State \\ Technical University \\ Kemerovo, Russian Federation \\ brv.egpp@kuzstu.ru
}

\author{
Vladimir Efremenko \\ Department "Mining machines and \\ complexes" \\ T.F. Gorbachev Kuzbass State \\ Technical University \\ Kemerovo, Russian Federation \\ evm-47@mail.ru
}

\author{
Fedor Nepsha \\ Department "Power supply of mining \\ and industrial enterprises" \\ T.F. Gorbachev Kuzbass State \\ Technical University \\ Kemerovo, Russian Federation \\ nepshafs@gmail.com
}

\begin{abstract}
This paper discuss the features of reactive power compensation in electrical networks of coal open-cast minings. The authors calculated the value of the reactive power consumed by the network elements. It is established that synchronous motors are able to compensate about $40 \%$ of the total reactive power consumption in coal open-cast minings. The paper gives recommendations on the possibility of using synchronous motors as compensating devices in electrical networks of coal open-cast mining. The conducted researches showed that for compensating the reactive power consumed by other consumers, it is more appropriate to use additional compensating devices installed in the places of reactive power consumption.
\end{abstract}

Keywords - reactive power compensation, power losses, coal open-cast mining, synchronous motor, energy saving

\section{INTRODUCTION}

Energy saving issues are becoming increasingly important. For their solution the Russian government created numerous appeals and decrees of the President, resolutions of the Government, including Federal Law No. 261-FZ dated 23 Nov. 2009 "On Energy Saving and on Improving Energy Efficiency ..." [1]. In this aspect, the reduction of electric power losses in electric grids arising during its transmission and distribution is an actual and practically significant task. The need for timely solution of this task is due to various technical and economic reasons. The coal open-cast minings are complex energy-intensive consumers of electric power. Therefore reducing the energy losses in the electrical networks of coal open-cast minings makes possible to reduce their energy intensity, to save more energy resources and to realize the energy saving potential available in the coal industry today.

\section{THEORY}

Reactive power flows have a significant influence on the formation of the value of implementation power losses of electrical energy. Their presence increases the electrical power losses, decreases energy quality and transmission capacity of electric networks, leads to other negative consequences. For reducing the reactive power flows and electrical power losses in electrical networks, it is necessary to assume the measures for compensating reactive power consumption. Those measures consist in the installation of additional reactive power sources (compensating devices) at the place of its consumption [2].
In electrical networks of coal open-cast minings, synchronous motors (SM) can be used as such reactive power sources. The disposable reactive power $Q_{d s}$ of SM and the active power loss $\Delta P$ are functions of the synchronous motor (SM) stator load factor $m$ and the voltage at its terminals:

$$
Q_{d s}=f(m, U) ; \Delta P=(\psi, m, U),
$$

where $m=P / P_{\text {nom }}$ - relative units of the active power consumed by SM; $\psi=Q / Q_{\text {nom }}$ - relative value of the generated or consumed reactive power; $U$ is the relative value of the voltage at the motor terminals. In practice, the values of $m$ can vary from 0.05 (a mode close to the idle speed of SM) to 1.1 and $\psi$ from -0.6 (reactive power consumption mode) to $\psi_{d s}$ (relative value of the available reactive power SM at the considered values of $U$ and $m$ ). The main characteristics of synchronous motors are shown in Fig. 1, 2.

Fig. 1 shows the U-shaped characteristic of a synchronous machine. It follows from this that by changing the value of the excitation current; it becomes possible to regulate the motor power factor. When synchronous motor operates in under-excitation mode it consumes reactive power from the electrical network. When synchronous motor is switched to overexcitation mode, it begins to work not only as motor, but also as reactive power source, that is, it generates reactive power in the electrical network $[3,4]$. The magnitude of the reactive power generated by the synchronous motor depends on its active power load, the voltage at its terminals and the technical parameters of the motors.

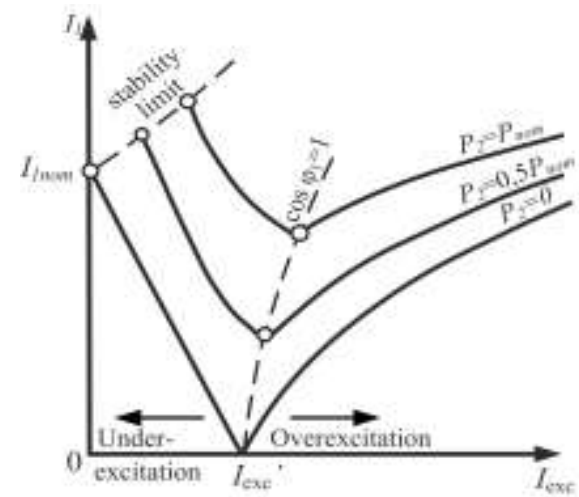

Fig. 1. U-shaped characteristic 


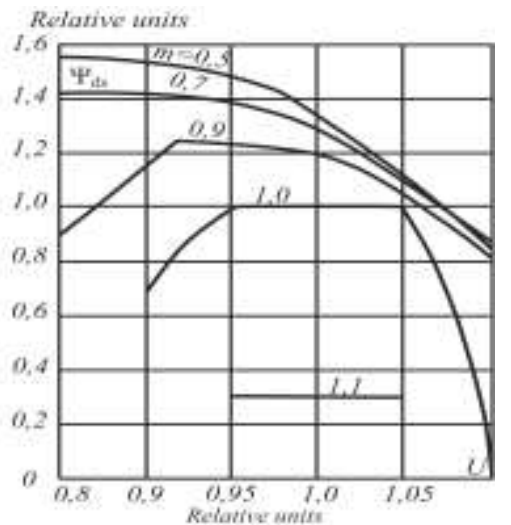

Fig. 2 shows the dependence of the change in the relative value of the SM available reactive power on the motor load factor at the active power $\mathrm{m}$ for different values of the voltage at the terminals of the motor $U$.

Thereby, it seems expedient to determine the generating capacity for reactive power of synchronous motors installed on coal open-cast minings. It is necessary for evaluating the effectiveness of their use as compensating devices for reactive power compensation in the electrical networks of coal open-cast minings.

Fig. 2. The dependence of the change in the relative value of the reactive power available on SM depending on the voltage at the motor terminals $U$

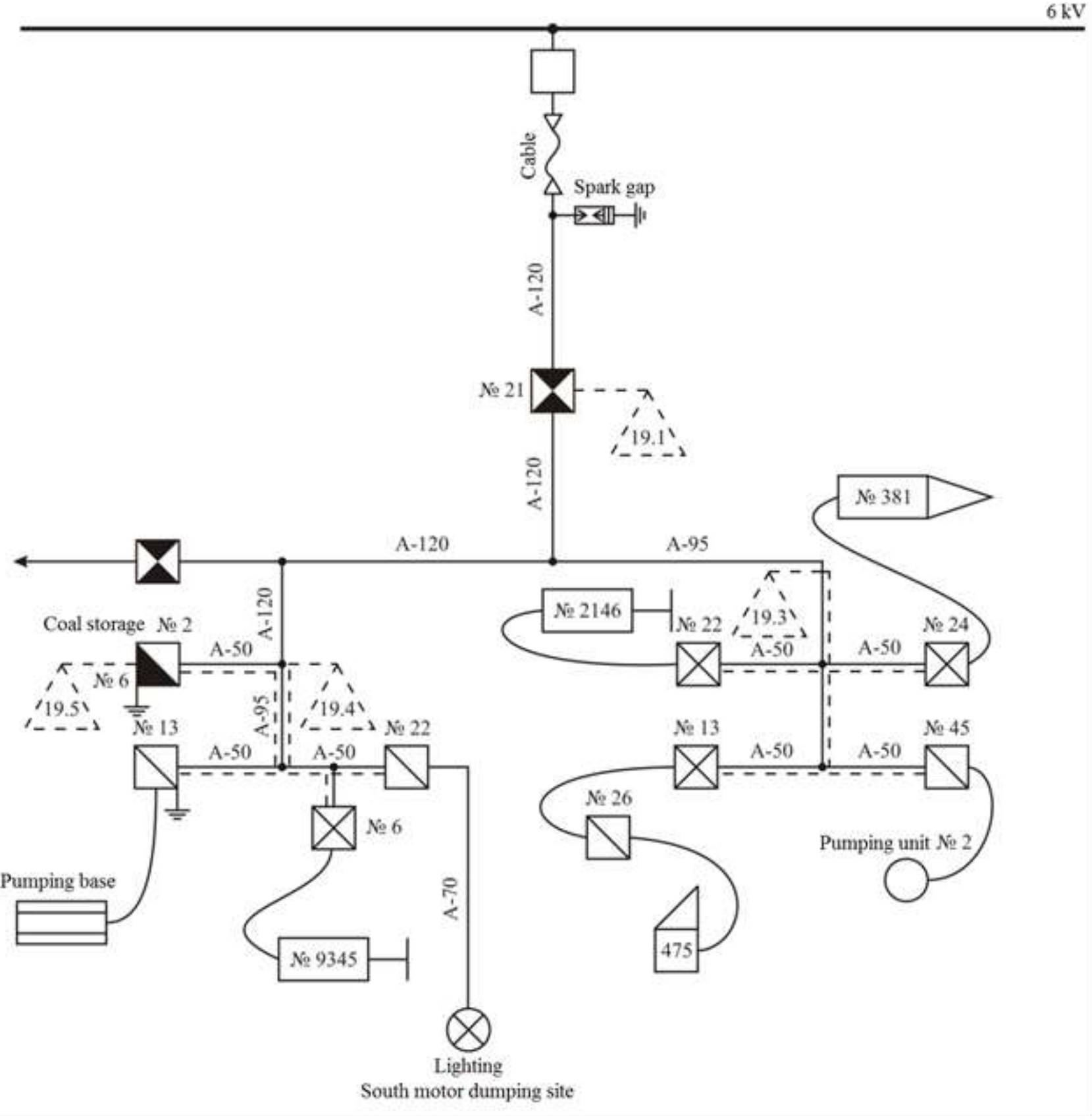

Fig. 3. Scheme of power supply system of the mining operation site of the coal open-cast mining 
For this purpose, the authors examined the power supply system of coal open-cast mining. The considered power supply system of the coal open-cast mining is carried out from a two-transformer substation of $110 / 6 \mathrm{kV}$ with installed capacity of power transformers $2 \times 10000 \mathrm{kVA}$. The coal open-cast mining has six mining operation sites. In Fig. 3 as an example, the scheme of power supply of one of the mining operation site is given. The main consumers of electrical energy in the section are excavators, drilling rigs and pumping units. The electric drive of excavators is carried out mainly with the help of synchronous motors. The electric drive of single-bucket excavators (type EKG-5A) and drilling rigs is carried out with the help of high-voltage and low-voltage asynchronous motors (AM). In addition to the consumers of the mining operation site, in the coal opencast mining there are also other electrical power consumers like coal ware-houses, boiler houses, administrative and residential buildings etc.

To determine the value of the reactive power consumed by the coal open-cast mining, the authors calculated the electric load using the demand coefficient method. The initial data for the calculation were the information on the installed capacity of the consumers of the mining operation site and the values of their demand and power factors (reactive power). The reactive power consumed by power transformers was determined using their passport data. Calculation and subsequent analysis was performed for the nominal load mode of electrical equipment. The results of calculating the reactive power consumed by the coal opencast mining are presented in the Table I.

TABLE I. REACTIVE POWER IN POWER SUPPLY SYSTEM OF THE COAL OPEN-CAST MINING

\begin{tabular}{|l|c|c|c|}
\hline \multirow{2}{*}{ Consumers } & $\begin{array}{c}\text { SM in the mode } \\
\text { of reactive power } \\
\text { consumption }\end{array}$ & \multicolumn{2}{|c|}{$\begin{array}{c}\text { SM in the mode of } \\
\text { reactive power } \\
\text { generation }\end{array}$} \\
\cline { 2 - 4 } & $\boldsymbol{Q}_{\text {cons, } \boldsymbol{k V A r}}$ & $\boldsymbol{Q}_{\text {cons, } \boldsymbol{k V A r}}$ & $\boldsymbol{Q}_{\text {gen }}, \boldsymbol{k V A r} \boldsymbol{r}$ \\
\hline Excavators (SM) & 4135.59 & 0.00 & 4604.25 \\
\hline $\begin{array}{l}\text { Excavators, } \\
\text { drilling machines } \\
\text { (AM) }\end{array}$ & 924.75 & 924.75 & \\
\hline $\begin{array}{l}\text { Power } \\
\text { transformers, } \\
\text { including: }\end{array}$ & 1075.347 & 1075.347 & \\
\hline $\begin{array}{l}\text { - site of mining } \\
\text { operations }\end{array}$ & 182.32 & 182.32 & \\
\hline - other consumers & 893.027 & 893.027 & \\
\hline $\begin{array}{l}\text { Auxiliaries } \\
\text { transformers }\end{array}$ & 238.04 & 238.04 & \\
\hline $\begin{array}{l}\text { Lighting } \\
\text { installations }\end{array}$ & 553.39 & 553.39 & \\
\hline Others & 3882.77 & 3882.77 & \\
\hline $\begin{array}{l}\text { Total for the coal } \\
\text { open-cast mining, } \\
\text { including: }\end{array}$ & 10809.90 & 6674.30 & 4604.25 \\
\hline $\begin{array}{l}\text { - mining operation } \\
\text { site }\end{array}$ & 6034.10 & 1898.50 & \\
\hline - other consumers & 4775.80 & 4775.80 & \\
\hline
\end{tabular}

As follows from the table, the main part of the reactive power consumed by the coal open-cast mining is represented by electric motors, power transformers of 6 / 0.4 $\mathrm{kV}$ pack-age transformer substations, auxiliaries transformers and lighting installations with mercury-vapor lamps. At the same time, a significant part of the reactive power is consumed by the electric receivers of other consumers. When the synchronous motors available in the coal open-cast mining are switched to overexcitation mode with the advance $\cos \varphi=0.8$, their generating capacity will be $4604.25 \mathrm{kVAr}$. Thus, when synchronous motors operate in this mode they are able to compensate about $40 \%$ of the total reactive power consumed by the coal open-cast mining. However, it should be noted that synchronous motors used as reactive power sources are installed in the mining operation site and therefore they can be used primarily to compensate the reactive power of the consumers of this mining operation site. In this case, the reactive power of the consumers of the mining operation site will be fully compensated, and the rest of the reactive power can be used to compensate the reactive power of other consumers. In addition, with a decrease in the active load of synchronous motors, it becomes possible to additionally load them by reactive power and generate reactive power in the electrical network while maintaining the same value of the total power transmitted over the electrical network. Consequently, in this case synchronous motors can be considered as a sufficiently effective means for compensating reactive power. At the same time, the use of synchronous motors for compensating the reactive power of other consumers is not entirely appropriate because other consumers are located far enough from the mining operation site, and hence from the synchronous motors. In this case the transfer of reactive power leads to additional losses of electric power in the electrical networks of the mining operation site. To compensate the reactive power consumed by other consumers it will be more appropriate to use additional compensating devices installed in the places of direct reactive power consumption. For example it can be complete capacitor banks installations.

At present, there are a large number of complete capacitor banks installations. They are represented by unregulated and adjustable batteries of static capacitors having several stages. In fact, the existing level of industrial development makes possible to release the shunt capacitor banks (SCB) of any configuration and capacity. Adjustable SCB have an increased cost compared to unregulated ones, but they allow achieving a greater reduction in energy losses.

For taking into account the reduction in power losses achieved by controlling the power of the SCB (or simply by cutting off the SCB at certain hours), it is possible to set the control algorithm based on load schedules. The most common is the algorithm for controlling the SCB power factor. However, the best results are obtained by a control algorithm based on the minimum power loss criterion.

The authors consider that while determining the SCB configuration on coal open-cast minings, it is necessary to take into account the following factors:

1. Change of consumed reactive power in time (graphs of reactive loads). In this case, it is advisable to consider load graphs having different discreteness. It determines the frequency of switching on and off of the individual voltage regulation stages [5]. 
2. The ability to control the power of the SCB (or disable SCB in the hours of the minimum loads). Stepwise regulation of reactive power implies the elimination of the phenomenon of overcompensation, ensuring the maximum effective value of $\cos \varphi$.

3. The influence of the power of the SCB on the electrical network mode by changing the voltage. Voltage regulation is one of the ways to reduce the loss of active power, therefore, along with optimizing the placement of the $\mathrm{SCB}$, it is advisable to consider the optimization of the voltage level $[6,7]$.

4. Temperature dependence of the active resistances of electrical network elements. Taking into account the temperature dependence makes possible to perform a correct calculation of the resistance of the electrical network taking into account the actual climatic conditions [8].

5. Taking into account the increase of active power losses in the SCB in the presence of higher harmonic. With the advent of frequency converters on excavators, the task of optimizing the configuration of the SCB is complicated in connection with the appearance of higher harmonics. While estimating the efficiency of compensation of reactive power it is necessary to take into account the factor of increasing electrical power losses due to the presence of higher harmonics generated by frequency converters.

Nonsinusoidal voltage and current lead to additional power losses in the main power elements of the power system. It makes difficult to compensate for reactive power with the help of reactive power compensation devices, shortens the service life of electrical machines, leads to the emergence of additional vibration of electric machines, devices of automatics, telemechanics and communication.

The authors note that there are no specific methods for selecting the SCB configuration for the power supply system of coal open-cast minings. Therefore the development of the method for selecting the SCB configuration in electrical networks of coal open-cast mining is an important, scientific and technical task.

\section{CONCLUSION}

The usage of proposed method of reactive power compensation will significantly reduce the amount of reactive power consumed by coal open-cast minings. Theoretical analysis shows that this method can consume about $40 \%$ of the total power, and the effect is very obvious.

In addition, when carrying out organizational measures to compensate for reactive power in mining operation sites, it becomes possible to provide an additional reduction in the reactive power consumed without resorting to significant capital expenditures. The number of organizational measures includes replacement of low-loaded power transformers and asynchronous motors, limitation of idling time, improvement of repair quality of electrical equipment, etc.
As the researches showed, the need for such measures is conditioned by the fact that the decrease in load of transformers and asynchronous motors leads to significant increase in the relative consumption of reactive power [913]. Reducing the consumed reactive power leads to a decrease in the implementation power losses in electric networks, an increase its quality. Consequently it facilitates the implementation of the potential for energy saving in coal open-cast minings.

The results of this paper can be used for reference to improve the utilization efficiency and reduce the energy losses in the electrical networks.

\section{REFERENCES}

[1] On Energy Saving and on Improving Energy Efficiency and on Amending Certain Legislative Acts of the Russian Federation. Federal Law 261-FZ, dated 23 Nov. 2009 (edited 29.07.2017).

[2] F. Nepsha, V. Efremenko, "Definition of static voltage characteristics of the motor load for the purpose of increase in energy efficiency of coal mines of Kuzbass", The 3nd international innovative mining symposium (devoted to Russian Federation year of environment), E3S Web of Conferences 21, 02002, 2017.

[3] V. Efremenko, R. Belyaevsky, and E. Skrebneva. "The increase of power efficiency of underground coal mining by the forecasting of electric power consumption", The 3nd international innovative mining symposium (devoted to Russian Federation year of environment), E3S Web of Conferences 21, 02002, 2017.

[4] V. Efremenko, R. Belyaevsky, "Evaluation of explosion protection means of mine electrical equipment for operation in excavations of coal mines", MINING 2014: Taishan Academic Forum - Project on Mine Disaster Prevention and Control, 2014, pp. 190-194.

[5] Z. Hanzelka,. "Reactive power compensation", in Electrical energy efficiency: technologies and applications, edited by Sumper A. \& Baggini A., John Willey \& Sons, Chichester 2012, pp. 371-398.

[6] J. Jajczyk, Z. Stein, and M. Zielińska, "The problems of reactive power compensation in low-voltage network of an industrial plant provided with asymmetric receivers", Academic Journals Electrical Engineering,, vol. 64, Poznan University of Technology, Poznań 2010, pp. 17-27.

[7] R Shlueter, "A voltage stability security assessment method [J]." IEEE Trans on PowerSystems, 1998, 13(4), pp. 1423-1438.

[8] R. Pandey, A. K. Kori, "Real and Reactive Powerflow Control Using Flexible Ac Transmission System Connected to a Transmission Line: a Power Injection Concept", International Journal of Advanced Research in Computer Engineering \& Technology (IJARCET) ISSN:2278 - 1323, Volume 1, Issue 6, August 2012.

[9] V. Efremenko, R. Belaevsky, "The analysis of influence of power transformers' load on consumption of reactive power", The bulletin of KuzSTU, 2009, vol. 6, pp. 46-48.

[10] V. Efremenko, R. Belaevsky, "The analysis of dependence of reactive power factor from power transformers' load factor", The bulletin of KuzSTU, 2010, vol. 1, pp. 107-109.

[11] R. Belaevsky, "Analysis of influence of the factor of the loading of asynchronous engines for consumption of reactive power", The bulletin of KuzSTU, 2010, vol. 6, pp. 66-69.

[12] S. Rahimi, M. Marinelli, and F. Silvestro, "Evaluation of Requirements for Volt/Var Control and Optimization Function in Distribution Management Systems", In Proceedings of 2012 IEEE International Energy Conference and Exhibition, 2012, pp.331-336.

[13] H. F. Bilgin, M.Ermis, and A. Cetin, "Reactive-Power Compensation of Coal Mining Excavators by Using a New-Generation STATCOM". IEEE transactions on industry applications, 2007, pp. 97-109. 